\title{
Simulation study of a naturally-ventilated building integrated photovoltaic/thermal (BIPV/T) envelope
}

\begin{abstract}
This paper addresses the simulation of a partially transparency, ventilated PV facade integrated into the envelope of an energy efficient building. Such an arrangement exploits the heat transfer between cavity air, the PV façade and the primary wall of the building for the purpose of PV cooling in summer (with natural convection) and heat recovery in winter (mechanical ventilation). A simplified physical model of the system is proposed for the summer operating configuration, which is more challenging from a numerical perspective. The model describes the active envelop in terms of a simplified geometry, and includes parameters such as density of PV cells, relative coverage of degree of transparency/opaque surfaces, and the ratio of height/width of the double-skin. For a given set of meteorological conditions, the surface and air temperatures, mass flow rate and PV power output are obtained by solving a system of thermal and aerodynamic balance equations. Validation of the model was undertaken using experimental data from a full scale prototype system installed in Toulouse, France as part of the RESSOURCES project (ANR-PREBAT2007). Coupling of the system to a simulated building was achieved with the aid of TRNSYS, and this combined system was evaluated in terms of heating and cooling needs for a range of French climates. It was found that the cooling needs are marginally higher for all locations considered, whereas the impact of the façade on the heating needs is weak as these needs are already low for these all locations.
\end{abstract}

Keyword: Naturally-ventilated; PV; Double-skin façade; BIPV 